\title{
Integration of peroxide delignification and sulfamic acid sulfation methods for obtaining cellulose sulfates from aspen wood
}

\section{Boris Kuznetsov ${ }^{1,2}$ *, Vladimir Levdansky ${ }^{1}$, Svetlana Kuznetsova ${ }^{1,2}$, Natalya Garyntseva ${ }^{1}$, Irina Sudakova ${ }^{1}$, Alexander Levdansky ${ }^{1}$}

\begin{abstract}
New method of cellulose sulfates obtaining from available and inexpensive raw material - aspen wood was developed. This method integrates catalytic peroxide delignification and sulfamic acid sulfation stadies. Such solvents as acetic acid and water were used for isolation of pure cellulose by wood peroxide delignification with $\mathrm{TiO}_{2}$ catalyst. Low-aggressive and less-toxic sulfating agent - sulfamic acid - urea mixture was used for obtaining of cellulose sulfates.
\end{abstract}

\section{Introduction}

Biologically active cellulose sulfates are used in perfumery, cosmetics, as sorbents materials and they have good prospects for application in medicine as antimicrobial, antiviral and anticoagulant agents (Zhang et al. 2015; Lin et al. 2012; Shibata 2011).

The most common raw material for obtaining of cellulose is the wood. At present the manufacture of cellulose from wood is an environmentally hazardous process because dangerous chemicals are involved in the wood delignification and pulp bleaching (Sixta 2006).

Catalytic delignification of wood in hydrogen peroxide- acetic acid - water medium at $120-130{ }^{\circ} \mathrm{C}$ allows producing the pure cellulose by one-step process without the use of ecology dangerous delignification and bleaching agents (Kuznetsov et al. 2008). But the different side reactions of low molecular mass products condensation with the formation of so-called "pseudo-lignin" ( $\mathrm{Hu}$ et al. 2012) take place in wood peroxide delignification at elevated temperatures. The intensive mixing of a reaction medium and the fine grinding of wood were used to prevent the condensation reactions in aspen wood peroxide delignification with sulphuric acid catalyst (Kuznetsov et al. 2013). At these conditions the pure cellulose with a low content of residual lignin (less $1 \%$ ) was obtained from sawdust of aspen wood at temperature $100{ }^{\circ} \mathrm{C}$ and atmospheric pressure. The obtained cellulose is suitable for the production of different ethers, including cellulose sulfates.

Methods of cellulose sulfates obtaining commonly use such sulfating agents, as $\mathrm{H}_{2} \mathrm{SO}_{4}$, (Chen et al. 2013) $\mathrm{SO}_{3}$, (Qin et al. 2014) $\mathrm{ClSO}_{3} \mathrm{H}$ (chlorosulfonic acid) with solvents Py, DMF, DMSO (Zhu et al. 2014), 1,4-dioxane, (Kuznetsov et al. 2015) ionic liquids (Wang et al. 2009) and others. The most effective sulfating agents are complexes of $\mathrm{SO}_{3}$ with organic bases such as tertiary amines, Py, DMF, etc. However, $\mathrm{SO}_{3}, \mathrm{H}_{2} \mathrm{SO}_{4}$, and $\mathrm{ClSO}_{3} \mathrm{H}$ are rather aggressive and toxic reagents.

\footnotetext{
*Corresponding author. Tel.: +7 39124948 94. Fax: +7 39120519 42. E-mail: bnk@icct.ru; inm@icct.ru (B.N. Kuznetsov)

${ }^{1}$ Institute of Chemistry and Chemical Technology SB RAS; Federal Research Center "Krasnoyarsk Science Center SB RAS” Akademgorodok, 50-24, Krasnoyarsk, 660036, Russia

${ }^{2}$ Siberian Federal University, Svobodnyi, 79, Krasnoyarsk 660041, Russia
} 
Less dangerous sulfating agent is the sulfamic acid, which produced in industry by the reaction of urea with $\mathrm{H}_{2} \mathrm{SO}_{4}$. The use of sulfamic acid for cellulose sulfation in an $\mathrm{N}_{2} \mathrm{O}_{4}-$ DMF system was reported (Wagenknecht et al. 1993). But the degree of substitution of cellulose sulfates obtained by this method was less than 0.4 under the conditions employed.

The direct sulfation of cellulose with $\mathrm{NH}_{2} \mathrm{SO}_{3} \mathrm{H}$ in DMF was described (Zhang et al. 2011). In comparison with chlorosulfonic acid, the sulfamic acid reacts with cellulose only at elevated temperature $\left(70-80{ }^{\circ} \mathrm{C}\right)$. Obtained cellulose sulfates were soluble in water and had degree of substitution 1.78-1.89. The main disadvantage of this method is a quite long reaction time (up to $24 \mathrm{~h}$.). In paper (Huang and Zhang 2010) the reaction of cotton cellulose with $\mathrm{NH}_{2} \mathrm{SO}_{3} \mathrm{H}$ was carried out in a laboratory oven at high temperature which promoted the partial destruction of sulfated products.

The results of the study of new method of cellulose sulfates obtaining from aspen wood, which integrates the stages of pure cellulose isolation by wood peroxide delignification with $\mathrm{TiO}_{2}$ catalyst and further sulfation of cellulose by sulfamic acid-urea mixture are described in the present paper. In contrast to previously studied method of aspen wood oxidative delignification with $\mathrm{H}_{2} \mathrm{SO}_{4}$ catalyst (Kuznetsov et al.2013) the non-toxic and non-corrosive $\mathrm{TiO}_{2}$ catalyst is used for pure cellulose isolation from aspen wood under mild conditions $\left(100^{\circ} \mathrm{C}, 0.1 \mathrm{MPa}\right)$. The less-aggressive and less-toxic sulfating agent - sulfamic acid-urea mixture is employed for cellulose sulfation instead of dangerous traditional sulfating agents (e.g. chlorosulfonic acid-pyridine mixture).

\section{Materials and methods}

\subsection{Cellulose obtaining from aspen wood}

Air dry sawdust (fraction 2-5 mm) of aspen wood (Populus tremula L.) harvested in the forest area near Krasnoyarsk city was used as initial raw material. The chemical composition of aspen wood ( $\%$ on abs. dry wood) is 46.5 cellulose, 21.7 lignin, 23.5 hemicelluloses, 0.43 mineral part.

Cellulose was isolated from aspen wood using the original method of oxidative delignification by $\mathrm{H}_{2} \mathrm{O}_{2}$ with $\mathrm{TiO}_{2}$ catalyst under the mild conditions. Commercial $\mathrm{TiO}_{2}(\mathrm{GOST}$ 9808-84) with an average particle size near $10 \mu \mathrm{m}$, phase composition: rutil $92 \%$, anatase $8 \%$, BET surface area $3 \mathrm{~m}^{2} / \mathrm{g}$ was used as a catalyst.

Delignification of wood sawdust was carried out in a glass reactor of $250 \mathrm{~cm}^{3}$ volume supplied by mechanical stirrer, condenser and thermometer. Aspen wood sawdust ( $10 \mathrm{~g})$ was placed to the reactor and a mixture of acetic acid, hydrogen peroxide, distilled water and $\mathrm{TiO}_{2}$ was added. The reaction mixture was heated up to the required temperature and was vigorously stirred $(700 \mathrm{rpm})$ during $1-4 \mathrm{~h}$. After that the reaction mixture was cooled and the obtained cellulosic product was separated under vacuum using Buchner funnel, following washing by distilled water and drying at $105^{\circ} \mathrm{C}$ until constant weight.

Cellulosic product yield was estimated by gravimetric method and calculated as follows: yield $=\left(\mathrm{m} / \mathrm{m}_{\mathrm{o}} \times 100 \%\right.$, where $\mathrm{m}$ is the mass of abs. dry cellulosic product $(\mathrm{g}), \mathrm{m}_{\mathrm{o}}$ is the mass of abs. dry wood $(\mathrm{g})$.

Three replicates were used for each case and average yields of cellulose were calculated. The deviations are given for experimental data in Tables 1 and 2.

\section{2 Sulfation of cellulose with sulfamic acid-urea mixture}

Cellulose $(1.62 \mathrm{~g})$, urea $(1.80 \mathrm{~g})$, sulfamic acid $(3.40 \mathrm{~g})$ and diglyme or DMF $(40 \mathrm{ml})$ were placed in a three necked flask $(100 \mathrm{ml})$ equipped with stirrer, thermometer and reflux. The mixture was boiled under reflux at vigorous stirring within 1-4 hours. After that, the mixture was cooled to $15-20{ }^{\circ} \mathrm{C}$, poured into $50 \mathrm{ml}$ of $75 \%$ water-ethanol solution containing 3-4 \% sodium hydroxide and stirred. The resulting sodium salt of cellulose sulfate was separated by filtration, washed with $96 \%$ ethanol, and dried under vacuum. The obtained product was then dissolved in 50-60 ml distilled water, filtered and dialyzed on cellophane against distilled water. After dialysis the aqueous solution of sodium salt of cellulose sulfate ( $\mathrm{NaCS}$ ) was concentrated under vacuum until complete removal of water. 
The yield of $\mathrm{NaCS}(\mathrm{Y})$ was calculated according to the Eq. 1:

$$
\mathrm{Y}=\mathrm{mol}(\mathrm{NaCS}) / \mathrm{mol}(\mathrm{Cell}) \times 100 \%(1)
$$

where mol ( $\mathrm{NaCS})$ - is the mol of $\mathrm{NaCS}(\mathrm{g})$ and mol (Cell) - is the mol of initial cellulose.

Three replicates were used in each case and average yields of $\mathrm{NaCS}$ were calculated. The deviations are given for experimental data throughout the text.

\subsection{Characterization methods}

Elemental analysis (C, H, N, S, O) was performed with the use of Flash EATM 1112 analyzer (Thermo Quest, Italy).

The degree of substitution $\left(\mathrm{DS}_{\mathrm{S}}\right.$ ) of cellulose sulfates was calculated according to the Eq.2 (Gericke et al. 2009):

$$
\mathrm{DS}_{\mathrm{S}}=\left(162.1 \times \mathrm{W}_{\mathrm{S}}\right) /\left(3207-102.1 \times \mathrm{W}_{\mathrm{S}}\right)(2)
$$

where $\mathrm{W}_{\mathrm{S}}$ - is the sulfur content $(\%)$.

The contents of cellulose, lignin and hemicelluloses in solid products were defined by analytical methods, common in wood chemistry (Sjöström and Alen 1999).

The content of cellulose was determined gravimetrically according to Kürschner and Hoffer. A portion of 1 g cellulosic product was weighed into an Erlenmeyer flask. $25 \mathrm{~mL}$ of a mixture of nitric acid in ethanol (1:4, v/v) was added followed by one-hour boiling under reflux. The solid was separated from the solution using a glass filter $(40 \mu \mathrm{m})$. This procedure was repeated twice and a third time with hot water for $30 \mathrm{~min}$. The glass filter was then dried at $105^{\circ} \mathrm{C}$ and weighed.

For the gravimetrical determination of holocellulose $0.3 \mathrm{~g}$ of cellulosic product was dispersed in $45 \mathrm{~mL}$ water and $60 \mu \mathrm{L}$ glacial acetic acid and $0.3 \mathrm{~g}$ sodium chlorite were added. The mixture was kept at $75^{\circ} \mathrm{C}$ in a shaking device for $5 \mathrm{~h}$. Acetic acid and sodium chlorite were added after every hour. Afterwards the holocellulose was separated by filtration using a glass filter $(40 \mu \mathrm{m})$, washed and dried at $105{ }^{\circ} \mathrm{C}$ and weighed (Rossberg et. al. 2014).

The content of hemicelluloses was calculated as the difference in weights of holocellulose and cellulose.

Acid-insoluble lignin (Klason lignin) was determined according the following procedure. $1 \mathrm{~g}$ of cellulosic product was placed in $100-\mathrm{mL}$ beaker and then added $15.0 \mathrm{~mL}$ of $72 \%$ sulfuric acid. The acid was added gradually in small increments while stirring and macerating the material with a glass rod. After the specimen was dispersed, the beaker was covered with a watch glass and kept it in a bath at $20^{\circ} \mathrm{C}$ for $2 \mathrm{~h}$. The material was stirred frequently during this time to ensure complete solution. Then the material was transferred from the beaker to the flask and $300 \mathrm{~mL}$ of water was added to a flask to dilute solution to $3 \%$ concentration of sulfuric acid. The solution was boiled for $4 \mathrm{~h}$, maintaining constant volume by using a reflux condenser. Then the lignin was transferred quantitatively on the filter, using hot water, washed and dried in an oven at $105.3{ }^{\circ} \mathrm{C}$ to constant weight (TAPPI 1998).

The lignin content was calculated in the test specimen as follows:

$$
\text { Lignin, } \%=\mathrm{A} \cdot 100 / \mathrm{W}
$$

where: A = weight of lignin, $g$

$\mathrm{W}=$ oven-dry weight of test specimen, $\mathrm{g}$

Intrinsic viscosity of cellulose was measured and degree of polymerization was calculated according to ASTM $1795-13.0,25 \mathrm{~g}$. of dry cellulose was placed in $100 \mathrm{ml}$ glass flask that can be tightly closed by screw cap. $25 \mathrm{ml}$ of distilled water was added to the flask and shook in order to disperse the cellulose sample. The air from the flask was swept out with a stream of nitrogen. $25 \mathrm{ml}$ of cupriethylenediamine was added, the cap was inserted tightly and the solution was shaken in a mechanical shaker bath at $20{ }^{\circ} \mathrm{C}$ until the cellulose completely dissolved. Then $10 \mathrm{ml}$ of the 
cellulose solution was transferred by pipette to a viscometer (VPG -3) previously placed in the temperature control bath at $20{ }^{\circ} \mathrm{C}$. The solution was left for at least $5 \mathrm{~min}$ to reach bath temperature. By applying suction, the solution into the lower line of the viscometer was drawn until top meniscus. The efflux time, the time required for the meniscus to pass from upper mark to the mark below, was measured at least three times. The outflow time of solvent was determined in the same condition.

The Mark-Houwink equation was used for the calculation of average degree of polymerization (Wang et al. 2016, Oberlerchner et al. 2015)

$$
[\eta]=\mathrm{K} \cdot \mathrm{M}_{\mathrm{r}}^{\alpha}
$$

All experiments were performed in triplicate and average values reported. Experimental errors, which were calculated as the relative standard deviation, are shown in text and in the tables.

FTIR analysis was carried out in transmission mode using the Tensor 27 spectrometer (Bruker, Germany). Samples of products ( $3 \mathrm{mg}$ for each) were prepared in pellet with matrix $\mathrm{KBr}$. The spectra were recorded in range $400-4000 \mathrm{~cm}^{-1}$ wavelength. Spectral data were processed by program OPUS/YR (version 5.0).

FT Raman spectra of the samples were recorded using Bruker RFS 100/S spectrometer with a liquid-nitrogen cooled Ge diode as detector over a range of 3500-100 $\mathrm{cm}^{-1}$. A cw-Nd:YAG-laser with an exciting line of $1064 \mathrm{~nm}$ was applied as light source for the excitation of Raman scattering. The analysis of the data was executed with OriginPro 7.0 (OriginLab Corp. MA USA).

X-ray diffraction analysis was carried out on PANalytical X'Pert Pro diffractometer using Cu-K $\alpha$ source $(\mathrm{A}=0.154$ $\mathrm{nm}$ ) in the $2 \Theta$ range $5-70^{\circ}$ and scanning step width of $0.01 \%$ scan.

Crystallinity index (CI) was calculated from the ratio of the height between the intensity of the crystalline peak $\left(\mathrm{I}_{002}\right.$ $\left.-\mathrm{I}_{\mathrm{AM}}\right)$ and total intensity $\left(\mathrm{I}_{002}\right)$ after subtraction of the background (Park et al. 2010).

${ }^{13} \mathrm{C}$ NMR spectra were recorded at temperature $25^{\circ} \mathrm{C}$ with spectrometer Bruker Avance III $600 \mathrm{MHz}$. The samples were dissolved in $\mathrm{D}_{2} \mathrm{O}$.

The electron images were obtained with scanning electron microscope TM-1000 HITACHI (Japan) with accelerating potential $15 \mathrm{kV}$. Samples were coated on carbon support.

\section{Results and discussion}

The developed method of cellulose sulfates obtaining from aspen-wood includes the steps of cellulose isolation by wood peroxide delignification in acetic acid-water medium in the presence of suspended $\mathrm{TiO}_{2}$ catalyst and the sulfation of obtained cellulose by sulfamic acid-urea mixture in diglyme or DMF (Fig. 1):

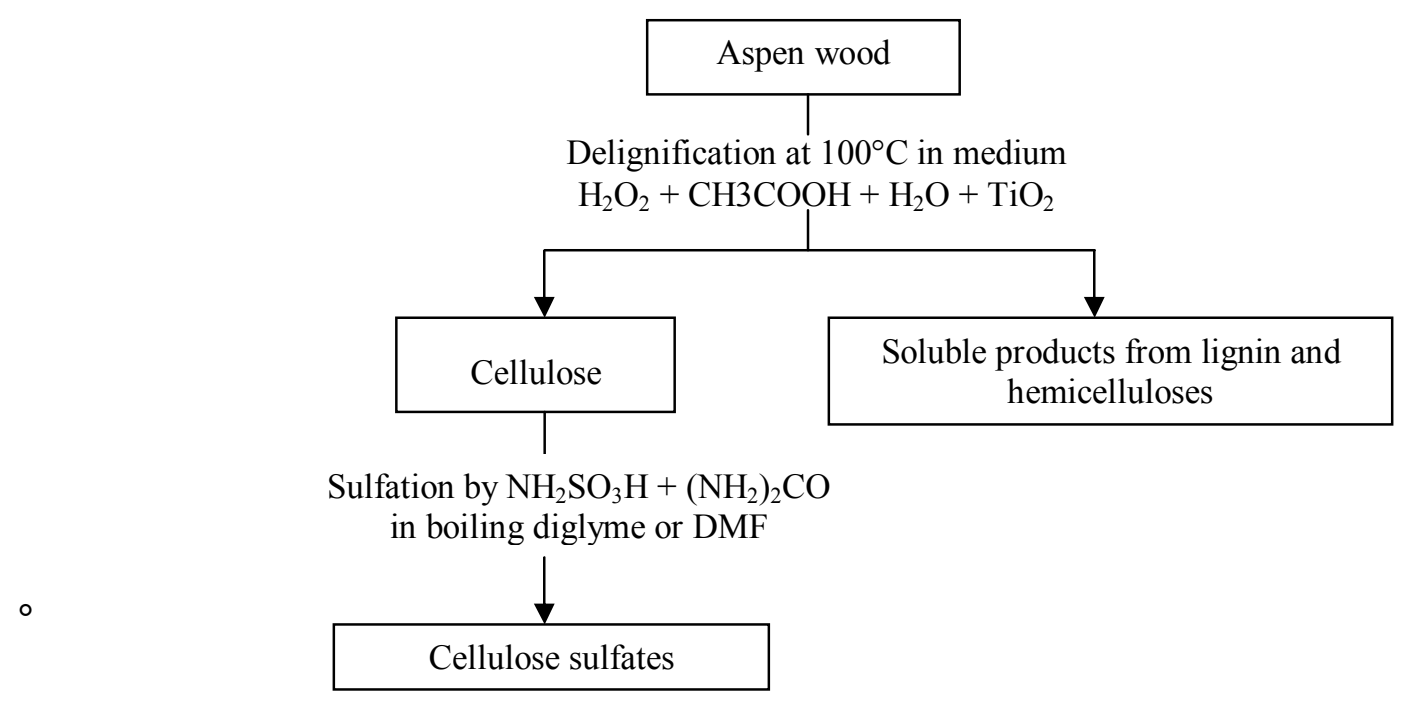

Fig. 1 Scheme of cellulose sulfates obtaining from aspen wood 


\subsection{Peroxide delignification of aspen wood with $\mathrm{TiO}_{2}$ catalyst}

In the present study the regularities of aspen wood delignification in the medium "hydrogen peroxide - acetic acid water" was first studied in the presence of solid $\mathrm{TiO}_{2}$ catalyst under mild conditions (temperatures $70-100{ }^{\circ} \mathrm{C}$, atmospheric pressure).

The influence of temperature, concentrations of hydrogen peroxide and acetic acid on the dynamics of lignin removal from wood was studied at fixed liquid/wood ratio (LWR) equal to 15.

The increase of temperature and time of delignification process significantly reduces the content of residual lignin in the cellulosic product (Fig. 2). But at the same time the yield of cellulosic product is decreased (Table 1).

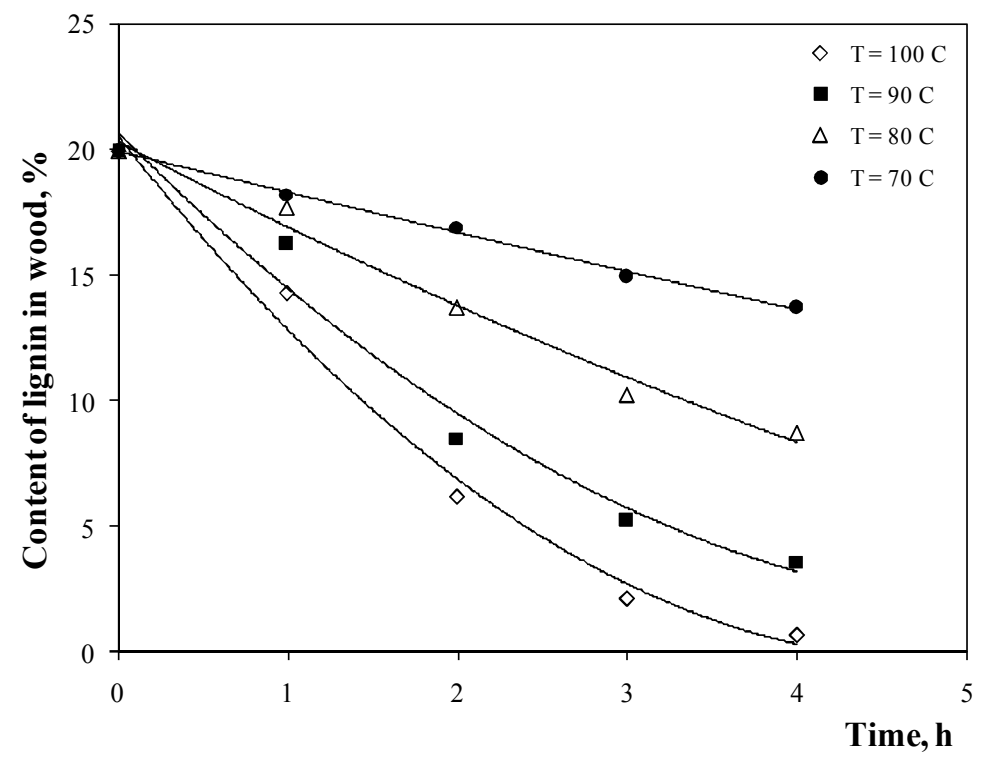

Fig.2 Dynamics of lignin removal from aspen wood in the presence of $1 \% \mathrm{TiO}_{2}$ catalyst at concentration of $\mathrm{H}_{2} \mathrm{O}_{2} 5 \%$, $\mathrm{CH}_{3} \mathrm{COOH} 25 \%$ and LWR 15

Table 1 Influence of delignification time on the yield and composition of cellulosic product Delignification conditions: $100{ }^{\circ} \mathrm{C}, \mathrm{H}_{2} \mathrm{O}_{2}-5 \%, \mathrm{CH}_{3} \mathrm{COOH}-25 \%$, LWR 15. Data represent percentages of oven dry weight (odw) (mean \pm SD)

\begin{tabular}{lcccc}
\hline Time, $\mathrm{h}$ & Yield of cellulosic product, $\%^{*}$ & \multicolumn{3}{c}{ Composition of product, $\%{ }^{* *}$} \\
\cline { 3 - 5 } & & cellulose & hemicelluloses & lignin \\
\hline 2 & $72.5 \pm 1.8$ & $85.8 \pm 1.9$ & $7.8 \pm 0.2$ & $6.1 \pm 0.2$ \\
3 & $62.5 \pm 1.6$ & $90.4 \pm 2.0$ & $7.2 \pm 0.2$ & $2.1 \pm 0.1$ \\
4 & $50.2 \pm 1.2$ & $93.5 \pm 2.1$. & $5.5 \pm 0.1$ & $0.7 \pm 0.1$ \\
\hline
\end{tabular}

"to the abs. dry wood ${ }^{* *}$ to the abs. dry cellulosic product

The cellulosic product obtained from aspen wood at temperature $100^{\circ} \mathrm{C}$ and time of delignification $4 \mathrm{~h}$ has the lowest content of residual lignin $(0,7 \%)$. These fixed temperature and time were used for study the impact of $\mathrm{H}_{2} \mathrm{O}_{2}$ and $\mathrm{CH}_{3} \mathrm{COOH}$ concentrations on the yield and composition of cellulosic product (Table 2). 
Table 2 Influence of concentration of $\mathrm{H}_{2} \mathrm{O}_{2}$ and $\mathrm{CH}_{3} \mathrm{COOH}$ on the yield and composition of cellulosic product obtained from aspen wood at $100^{\circ} \mathrm{C}$ and time $4 \mathrm{~h}$. Data represent percentages of oven dry weight (odw) (mean \pm SD)

\begin{tabular}{lcccc|ccc}
\hline & \multicolumn{3}{c|}{$\mathrm{H}_{2} \mathrm{O}_{2}, \% *$} & \multicolumn{3}{c}{$\mathrm{CH}_{3} \mathrm{COOH}^{*} \%{ }^{* *}$} \\
\cline { 2 - 7 } & 3 & 4 & 5 & 6 & 15 & 25 & 35 \\
\hline Yield, \% & $65.9 \pm 1.7$ & $50.8 \pm 1.3$ & $50.2 \pm 1.2$ & $49.8 \pm 1.2$ & $67.4 \pm 1.6$ & $50.2 \pm 1.2$ & $50.4 \pm 1.3$ \\
Composition, \%: & & & & & & & \\
cellulose & $85.7 \pm 2.1$ & $91.8 \pm 2.3$ & $93.5 \pm 2.1$ & $94.2 \pm 2.3$ & $84.4 \pm 1.9$ & $93.5 \pm 2.1$ & $92.0 \pm 2.3$ \\
hemicelluloses & $7.8 \pm 0.2$ & $6.3 \pm 0.2$ & $5.5 \pm 0.1$ & $5.3 \pm 0.1$ & $9.2 \pm 0.2$ & $5.5 \pm 0.1$ & $6.3 \pm 0.2$ \\
lignin & $6.2 \pm 0.2$ & $1.6 \pm 0.1$ & $0.7 \pm 0.1$ & $0.2 \pm 0.1$ & $6.1 \pm 0.2$ & $0.7 \pm 0.1$ & $0.2 \pm 0.1$ \\
\hline
\end{tabular}

*at $\mathrm{CH}_{3} \mathrm{COOH}$ concentration $25 \%$; **at $\mathrm{H}_{2} \mathrm{O}_{2}$ concentration $5 \%$

It was found, that the concentrations of $\mathrm{H}_{2} \mathrm{O}_{2}$ and acetic acid impact significantly on the content of residual lignin in cellulosic product. The increase of $\mathrm{H}_{2} \mathrm{O}_{2}$ concentration from 3 to $5 \%$ reduces the content of lignin in cellulose from 6.2 up to $0.7 \%$.

According to XRD data (Fig. 3), the unit cell of cellulosic product obtained from aspen wood is identical to the monoclinic unit cell of cellulose I (Nishiyama 2002). The crystallinity index of aspen cellulose (0.70) is a little less than that of the commercial microcrystalline cellulose (MCC) Vivapur 101 (0.75) (Park et al. 2010).

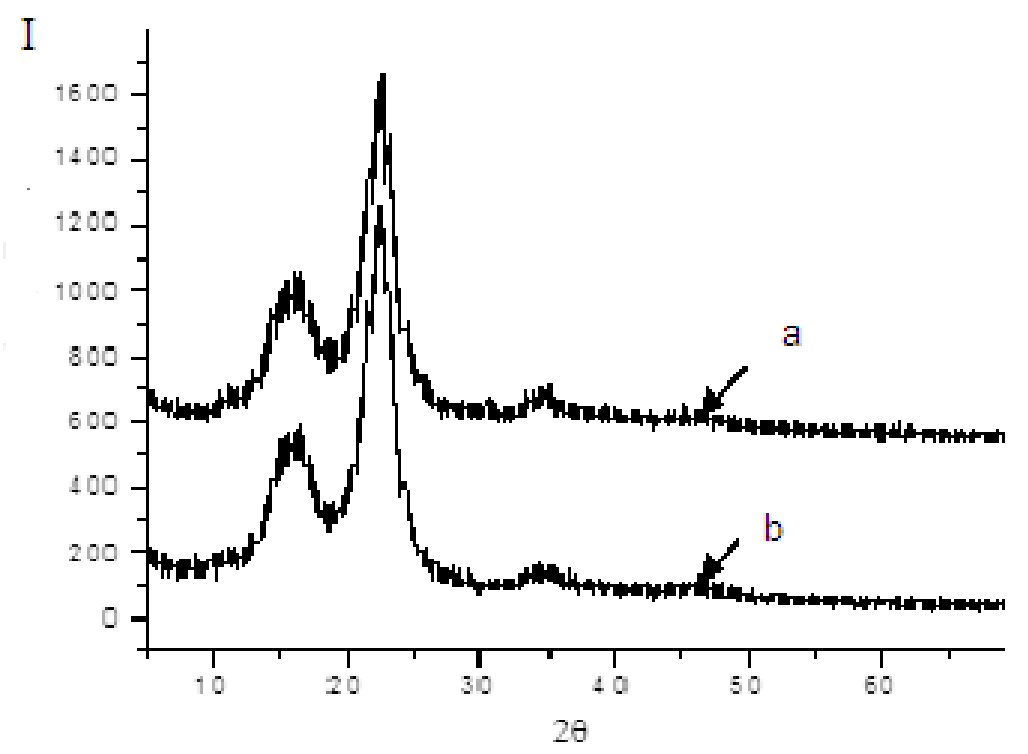

Fig. 3 XRD patterns of aspen wood cellulose (a) and of commercial MCC Vivapur 101 (b)

The similarity of FTIR spectra of cellulosic product from aspen wood and of industrial MCC Vivapur 101 (Fig. 4) indicates a similar composition of the both samples. In accordance with literature data (Fengel 1992) the broad absorption band in the region $3400-3500 \mathrm{~cm}^{-1}$ is due to vibration of hydrogen-bonding -OH groups and the absorption peak at $2900 \mathrm{~cm}^{-1}$ belongs to $\mathrm{CH}_{2}$ groups. The absorption peaks at $1164 \mathrm{~cm}^{-1}$ and at $896 \mathrm{~cm}^{-1}$ belong to vibrations of C$\mathrm{O}-\mathrm{C}$ and $\mathrm{C}-\mathrm{H}$ bonds, accordingly. 


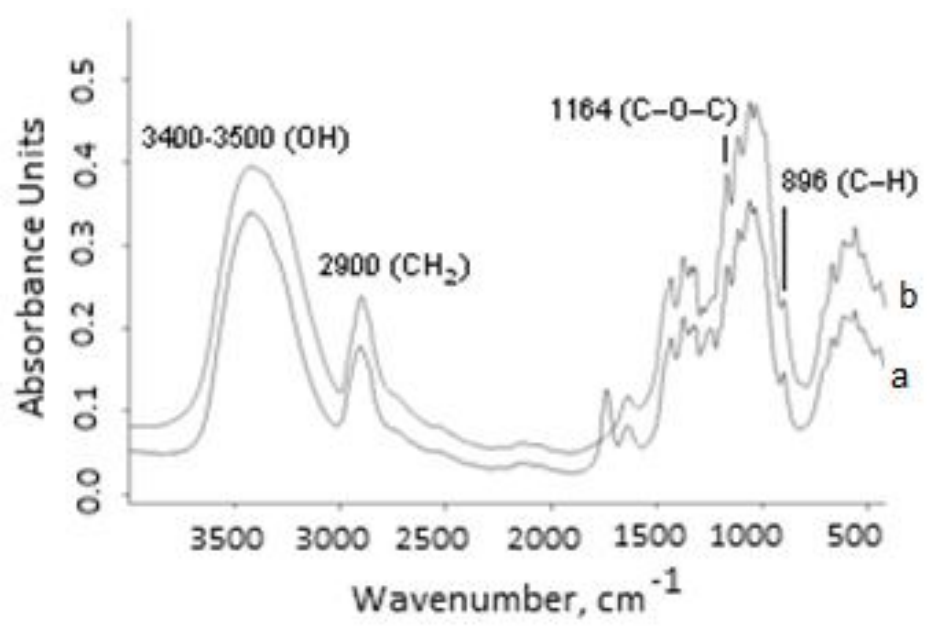

Fig. 4 FTIR spectra of cellulose obtained from aspen wood (a) and of MCC Vivapur 101(b)

The absence of peaks located in the range $1509-1609 \mathrm{~cm}^{-1}$, which correspond to vibrations of aromatic ring confirms the complete removal of lignin from cellulosic product. The absorption peak which corresponds to either the acetyl or uronic ester groups of hemicelluloses normally appears in the region $1700-1740 \mathrm{~cm}^{-1}$. The presence of absorption peak at $1735 \mathrm{~cm}^{-1}$ in spectrum of aspen cellulose indicates the presence of hemicelluloses in the sample.

According to SEM data the samples of cellulose from aspen wood and industrial MCC consist of microfibrils with different length (Fig. 5). Some of microfibrils are collected the bundles.

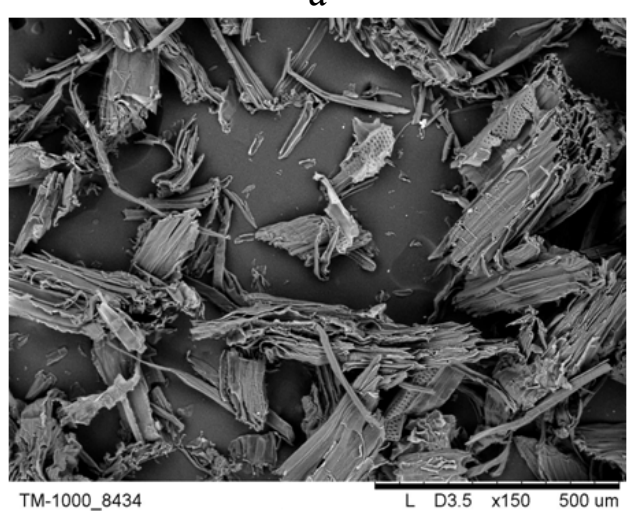

$\mathrm{b}$

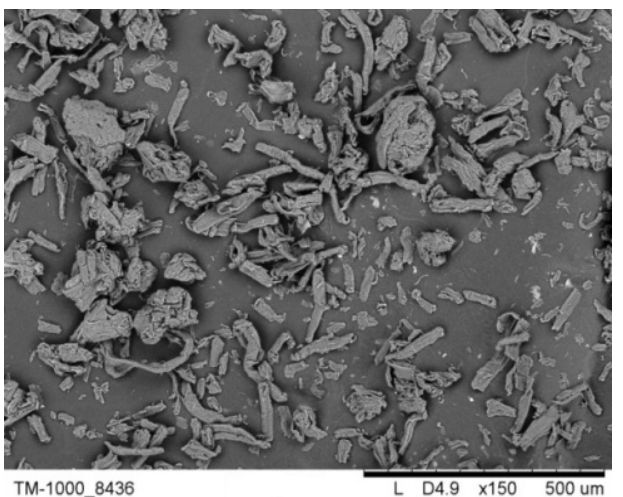

Fig.5 SEM images of cellulose, obtained from aspen wood with $\mathrm{TiO}_{2}$ catalyst (a) and of commercial MCC Vivapur 101 (b) at magnification 1000 times

As a result of the accomplished study the green method of aspen-wood peroxide delignification under the mild conditions in the medium of " $\mathrm{H}_{2} \mathrm{O}_{2}-\mathrm{CH}_{3} \mathrm{COOH}-\mathrm{H}_{2} \mathrm{O}-\mathrm{TiO}_{2}$ catalyst" was developed.

The regularities of aspen-wood peroxide delignification in acetic acid-water medium at $70-100{ }^{\circ} \mathrm{C}$ in the presence of $1 \% \mathrm{TiO}_{2}$ catalyst are the same as for catalyst $2 \% \mathrm{H}_{2} \mathrm{SO}_{4}$ (Kuznetsov et al. 2011). For both catalysts the increase of $\mathrm{H}_{2} \mathrm{O}_{2}$ and $\mathrm{CH}_{3} \mathrm{COOH}$ concentrations in the reaction mixture and time of the process reduced the content of residual lignin in cellulose product and decreased the yield of product. The peroxide delignification processes are described satisfactory by the first order equations for both of $\mathrm{TiO}_{2}$ and $\mathrm{H}_{2} \mathrm{SO}_{4}$ catalysts. But in contrast to $\mathrm{H}_{2} \mathrm{SO}_{4}$ catalyst, the $\mathrm{TiO}_{2}$ catalyst is non-toxic and corrosively non-active material. The more technologically convenient $\mathrm{TiO}_{2}$ catalyst at first was used for preparation of pure microcrystalline cellulose from aspen wood at mild conditions.

The cellulosic product containing $93.5 \%$ of cellulose, $5.5 \%$ of hemicelluloses $0.7 \%$ of lignin was isolated from aspen wood with the yield $50.2 \%$ at the next conditions of delignification process: temperature $100{ }^{\circ} \mathrm{C}$, concentrations 
of $\mathrm{H}_{2} \mathrm{O}_{2} 5 \%, \mathrm{CH}_{3} \mathrm{COOH} 25 \%$, $\mathrm{TiO}_{2} 1 \%$, LWR 15, time $4 \mathrm{~h}$. This product has the degree of polymerization $450 \pm 10$ and crystallinity index 0.70 , just like the commercial MCC.

The obtained cellulosic product was used for synthesis of cellulose sulfates.

\subsection{Sulfation of cellulose from aspen wood by sulfamic acid - urea mixture}

Chlorosulfonic acid $\left(\mathrm{ClSO}_{3} \mathrm{H}\right)$ is the common reagent for sulfation of cellulose (Zhu et al. 2014; Wang et al. 2007). In order to prevent the destruction reactions the sulfation of cellulose by chlorosulfonic acid is usually carried out below $30^{\circ} \mathrm{C}$. This makes possible to obtain cellulose sulfates with high degree of substitution (up to 1.70).

Since, $\mathrm{ClSO}_{3} \mathrm{H}$ is a corrosive, high toxic reagent, the less-toxic sulfamic acid is the best alternative. In this study the urea was used as a catalyst to improve the reactivity of $\mathrm{NH}_{2} \mathrm{SO}_{3} \mathrm{H}$ in the sulfation of cellulose from aspen wood. The higher activity of sulfamic acid - urea mixture in sulfation of polysaccharides (Al-Horani and Desai 2010) is explained by the formation of donor-acceptor complex:

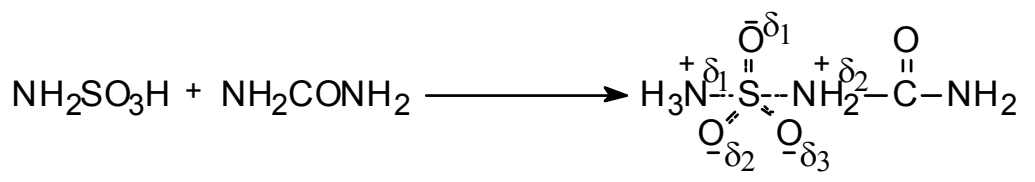

Cellulose sulfates, obtained with the use of sulfamic acid-urea mixture were isolated in the form of ammonium, sodium, and potassium salts according to scheme:

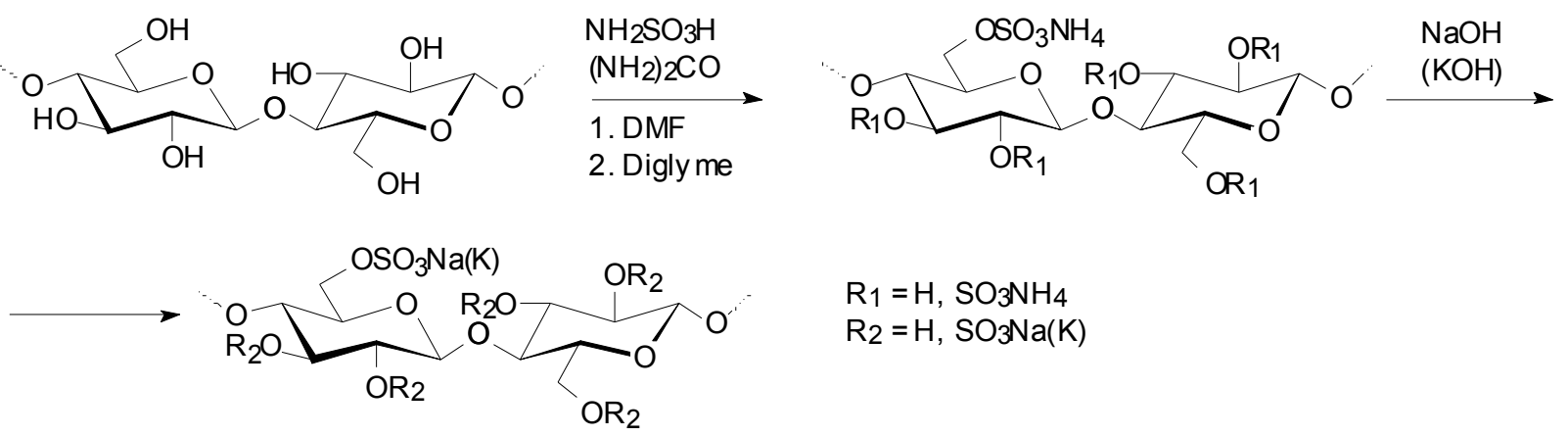

The reaction of cellulose sulfation by sulfamic acid - urea mixture in DMF or diglyme proceeds in a heterogeneous medium. Fig. 6 illustrates the variation of yield and sulfur content in cellulose sulfates with time of cellulose treatment by sulfamic acid-urea mixture.

a

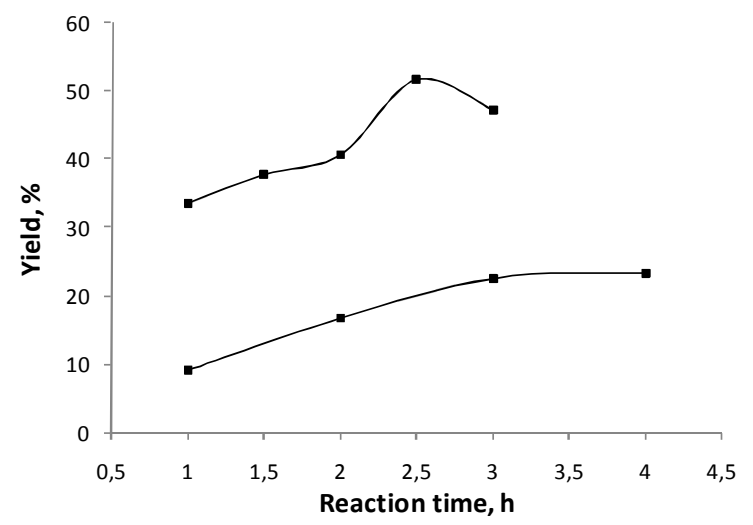

b

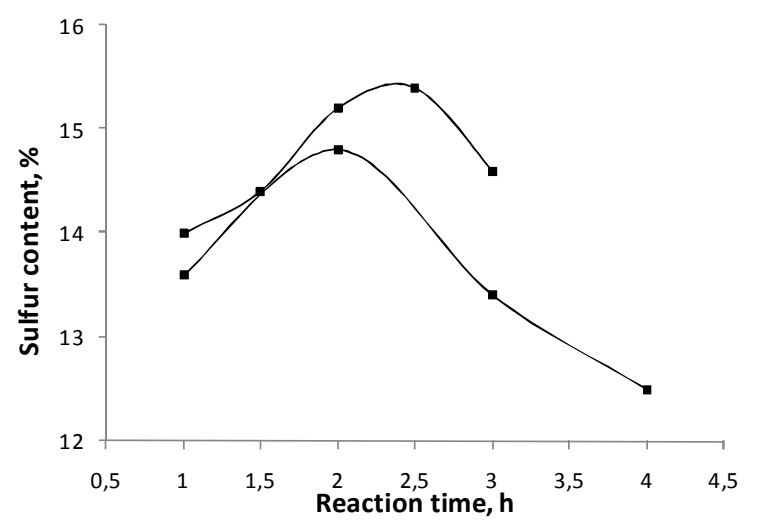

Fig. 6 Variation of yield (a) and sulfur content (b) in cellulose sulfates from aspen wood with time of cellulose treatment by sulfamic acid-urea mixture in diglyme (1) and in DMF (2) 
The rather high sulfur content in the cellulose sulfates obtained in diglyme (14.0 $\pm 0.3 \%)$ and in DMF $(13.6 \pm 0.3 \%)$ was observed at the reaction time $1 \mathrm{~h}$. At the reaction time $2-2.5 \mathrm{~h}$ the maximal sulphur content in cellulose sulfates reaches $15.2 \pm 0.4 \%$ in diglyme (after $2.5 \mathrm{~h}$ ) and $14.8 \pm 0.3 \%$ in DMF (after $2 \mathrm{~h}$ ). These values correspond to the degree of substitution 1.5 and 1.4, respectively. The further increase of the reaction time reduces the sulphur content in cellulose sulfates. The maximal yield of cellulose sulphate $(51.6 \pm 0.6 \%)$ was obtained in the presence of diglym after sulfation during $2.5 \mathrm{~h}$. This sample contains $15.4 \pm 0.4 \%$ of sulphur and it has the degree of substitution 1.53.

The sulfation of cellulose in boiling diglyme at $161^{\circ} \mathrm{C}$ results in less cellulose degradation than that in boiling DMF at $152{ }^{\circ} \mathrm{C}$. Besides, the use of diglyme as a solvent increases the yield of cellulose sulfate by 2.5 times as compared to DMF.

According to XRD data the disordering of cellulose crystalline structure takes place during sulfation process.

FTIR and Raman spectra of cellulose sulfates (Fig. 7, 8) contain the absorption peaks corresponding to vibrations of $\mathrm{C}-\mathrm{O}-\mathrm{S}$ and $\mathrm{O}=\mathrm{S}=\mathrm{O}$ bonds (Wang et al. 2007; Zhang et al. 2010). This confirms the presence of sulfate groups in the structure of cellulose.

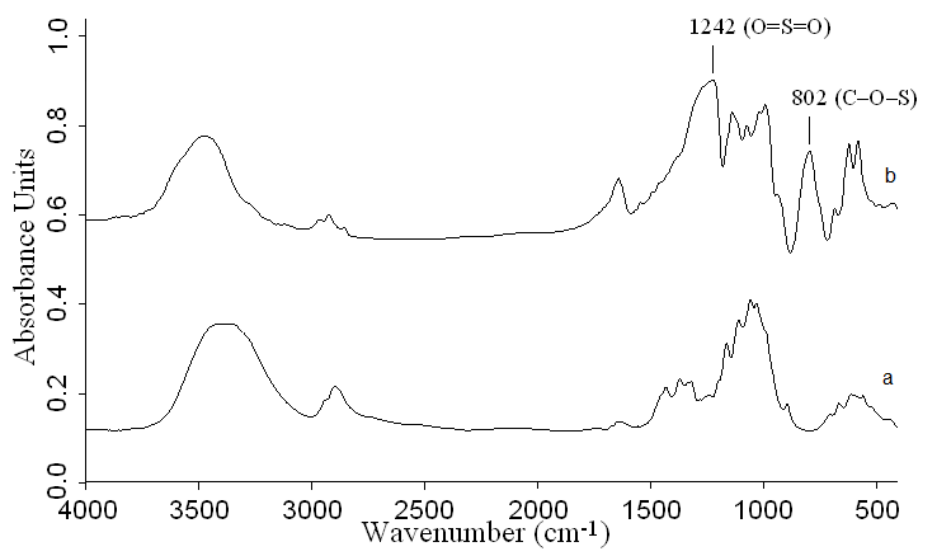

Fig. 7 FTIR spectra of initial cellulose from aspen wood (a) and of sodium salts of cellulose sulfate (b) obtained by sulfation of cellulose with sulfamic acid-urea mixture in diglyme (sulfur content $15.4 \pm 0.4 \%$ )

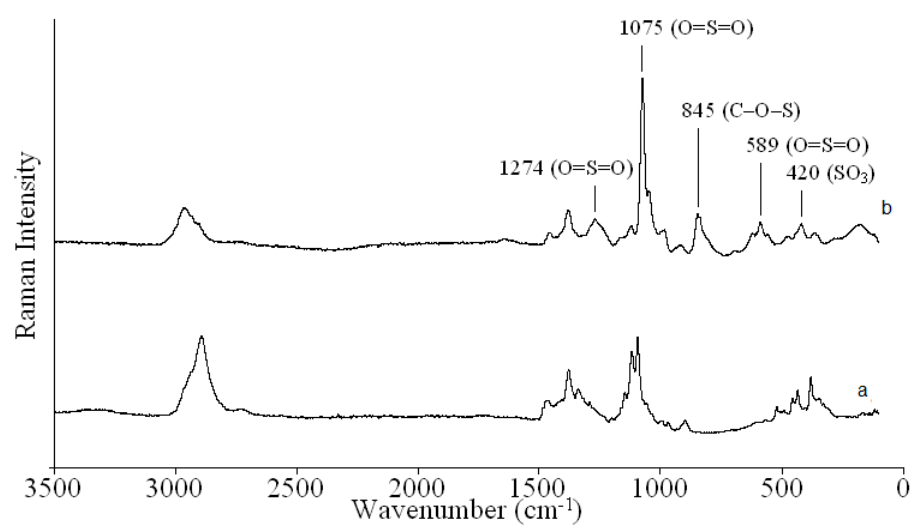

Fig. 8 Raman spectra of initial cellulose from aspen wood (a) and of sodium salts of cellulose sulfate (b) obtained by sulfation of cellulose with sulfamic acid-urea mixture in diglyme (sulfur content $15.4 \pm 0.4 \%$ )

It is known (Wang et al. 2007), that the hydroxyl group at C6 primary carbon atom is predominantly sulfated in a glucopyranose unit of cellulose: 


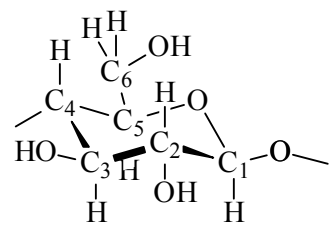

The hydroxyl group connected with carbon atom C2 is less reactive in the sulfation process. The hydroxyl group at C3 carbon atom is replaced on sulfate groups only under hard sulfation conditions, which promote the destruction of cellulose.

For cellulose sulfates the chemical shifts in ${ }^{13} \mathrm{C}$ NMR spectra corresponding to carbon atoms $\mathrm{C} 1$ - C6 in glucopyranose units of cellulose are observed at 102 (C1), 74 (C2), 73 (C3), 79 (C4), 77 (C5) and 60 (C6) ppm (Wang et al. 2007). The introduction of sulfate groups into cellulose moves the chemical shifts of carbon atoms to lower magnetic field (Table 3).

Table 3 Chemical shifts of carbon atoms in ${ }^{13} \mathrm{C}$ NMR spectra of cellulose and cellulose sulphates samples obtained from aspen wood

\begin{tabular}{lcccccc}
\hline \multicolumn{1}{c}{ Sample } & \multicolumn{5}{c}{ Chemical shift, p.p.m. } \\
\cline { 2 - 6 } & $\mathrm{C} 1$ & $\mathrm{C} 2$ & $\mathrm{C} 3$ & $\mathrm{C} 4$ & $\mathrm{C} 5$ & $\mathrm{C} 6$ \\
\hline Cellulose & 102.0 & 74.1 & 73.8 & 79.5 & 77.4 & 60.1 \\
& 100.3 & 74.5 & 72.8 & 78.9 & 77.5 & - \\
$\begin{array}{l}\text { Sodium salt of cellulose sulfate obtained with } \\
\text { the use of } \mathrm{NH}_{2} \mathrm{SO}_{3} \mathrm{H}-\text { urea mixture in DMF }\end{array}$ & - & 81.3 & - & - & - & 66.0 \\
& 100.6 & 74.6 & 72.8 & 78.7 & 77.6 & - \\
$\begin{array}{l}\text { Sodium salt of cellulose sulfate obtained with } \\
\text { the use of } \mathrm{NH}_{2} \mathrm{SO}_{3} \mathrm{H}-\text { urea mixture in diglyme }\end{array}$ & - & 80.9 & - & - & - & 66.2 \\
\hline
\end{tabular}

In ${ }^{13} \mathrm{C}$ NMR spectra of the obtained cellulose sulfates (Fig. 9) the signal of carbon atom C6 moves completely from 60 to $66 \mathrm{ppm}$. It means that all hydroxyl groups connected with carbon atoms C6 are substituted in cellulose sulfates on sulfate groups. Appearance of a new signal at 80-82 ppm indicates that only a part of OH-groups, connected with C2 atoms is substituted on sulfate groups in cellulose sulfates. No shift of a signal of C3 atom was observed, that indicates the absence of sulfate group at $\mathrm{C} 3$ atoms in cellulose sulfates.

a

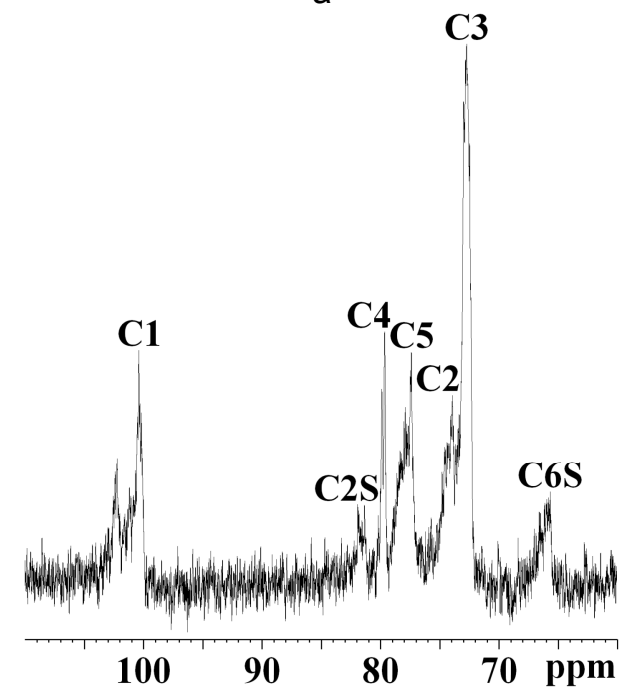

b

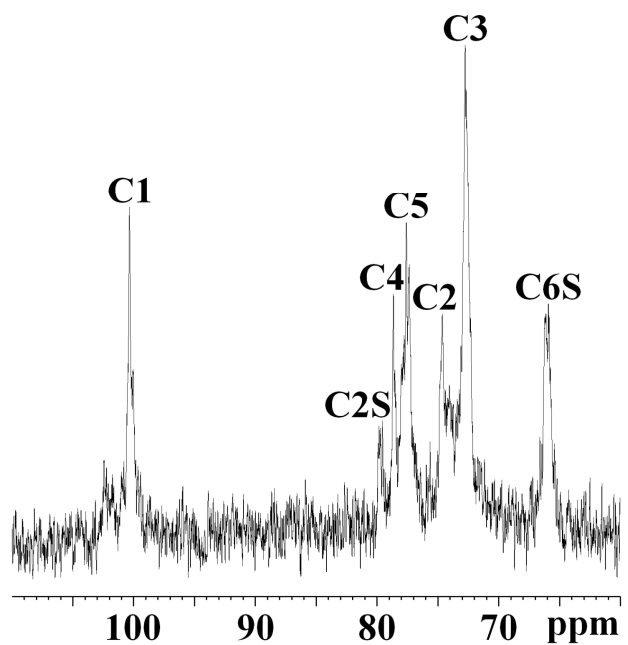

Fig. $9{ }^{13} \mathrm{C}$ NMR spectra of sodium salts of cellulose sulfates obtained by sulfation of cellulose with sulfamic acid-urea mixture in DMF (a) and in diglyme (b) (sulfur content $14.8 \pm 0.3$ and $15.2 \pm 0.4 \%$ respectively) 
The similar results were reported early for cellulose sulphates obtained with the use of another sulphating agents: $\mathrm{H}_{2} \mathrm{SO}_{4}$ (Chen et al. 2013), $\mathrm{SO}_{3}$ (Qin et al. 2014), chlorosulfonic acid (Kuznetsov et al. 2015, Zhu et al. 2014).

For the process of cellulose sulfation by different sulphating agents in the medium $\mathrm{N}_{2} \mathrm{O}-\mathrm{DMF}$ it was established that the sulphating activity increased in the range: $\mathrm{H}_{2} \mathrm{SO}_{4}<<\mathrm{NH}_{2} \mathrm{SO}_{3} \sim \mathrm{NOSO}_{4} \mathrm{H}<\mathrm{SO}_{2}<\mathrm{ClSO}_{3} \mathrm{H}_{2} \mathrm{SO}_{3}<\mathrm{SO}_{2} \mathrm{Cl}_{2}$ (Wagenknecht et al. 1993).

The regiospecificity is an important characteristic of cellulose sulfates that defines their properties. It is known from the literature that in obtaining cellulose sulfates by different sulfation methods the hydroxyl group at C6 carbon atom is predominantly sulfated while $\mathrm{OH}$-groups at carbon atoms $\mathrm{C} 2$ and $\mathrm{C} 3$ are less reactive in the sulfation process (Zhang et al. 2011, Roy et al. 2009). The results obtained for cellulose sulfation by sulfamic acid-urea mixture confirm this conclusion. The special methods of $\mathrm{OH}$-groups protection should be used to obtain regioselective cellulose sulfates (Fox et al. 2011, Zhang et al. 2010).

Developed method of cellulose sulfation by sulfamic acid-urea mixture has a number of advantages: sulfamic acid is less corrosive and less toxic then the traditionally used sulphating agents. In contrast to cellulose sulfation by sulfamic acid in the absence of urea (Wagenknecht et al. 1993, Zhang et al. 2011) the developed methods allows to obtain cellulose sulphates with more high $\mathrm{DS}_{\mathrm{s}}$ to reduce the cellulose destruction and the reaction time.

\section{Conclusion}

New method of cellulose sulfates obtaining from aspen wood was developed. This method integrates the stages of green peroxide catalytic delignification of wood in acetic acid - water medium and of cellulose sulfation by lessaggressive and less-toxic sulfating agent - sulfamic acid-urea mixture.

First the environmentally safe solid catalyst $\mathrm{TiO}_{2}$ was used for one-step obtaining of pure cellulose from aspen wood in the medium $\mathrm{H}_{2} \mathrm{O}_{2}-\mathrm{CH}_{3} \mathrm{COOH}-\mathrm{H}_{2} \mathrm{O}$ at temperatures $\leq 100^{\circ} \mathrm{C}$ and atmospheric pressure.

At selected conditions of wood peroxide delignification $\left(100{ }^{\circ} \mathrm{C}, 5 \% \mathrm{H}_{2} \mathrm{O}_{2}, 25 \% \mathrm{CH}_{3} \mathrm{COOH}, 1 \% \mathrm{TiO}_{2}\right.$, LWR 15 , time $4 \mathrm{~h}$ ) the cellulosic product containing $93.5 \%$ cellulose, $5.5 \%$ hemicelluloses and $0.7 \%$ lignin was obtained with the yield $50 \%$.

The conditions of effective sulfation of cellulosic product by sulfamic acid-urea mixture were selected. In contrast to cellulose sulfation by sulfamic acid in the absence of urea they allow to obtain the cellulose sulfates with the higher degree of substitution (up to 1.5). The yield of cellulose sulfates prepared in diglyme solvent was by 2.5 times higher than that in the medium of DMF.

\section{Acknowledgments}

The reported study was supported by Russian Science Foundation, grant № 16-13-10326.

\section{References}

Al-Horani RA, Desai UR (2010) Chemical sulfation of small molecules - advances and challenges. Tetrahedron 66:2907-2918

ASTM D1795 - 13 Standard Test Method for Intrinsic Viscosity of Cellulose

Chen G, Zhang B, Zhao J, Chen H (2013) Improved process for the production of cellulose sulfate using sulfuric acid/ethanol solution. Carbohyd Polym 95:332-337

Fengel D (1992) Characterization of cellulose by deconvoluting the OH valence range in FTIR spectra. Holzforschung 46:283-288 
Fox SC., Li B, Xu D, Edgar KJ (2011) Regioselective esterification and etherification of cellulose: a review. Biomacromolecules 12:P 1956-1972

Gericke M, Liebert T, Heinze T (2009) Interaction of ionic liquids with polysaccharides, 8 - synthesis of cellulose sulfates suitable for polyelectrolyte complex formation. Macromol Biosci 9:343-353

Hallac BB, Ragauskas AJ (2011) Analyzing cellulose degree of polymerization and its relevancy to cellulosic ethanol. Biofuels Bioprod Bioref 5:215-225

Hu F, Jung S, Ragauskas A (2012) Pseudo-lignin formation and its impact on enzymatic hydrolysis. Bioresource Technol 117:7-12

Huang X, Zhang WD (2012) Preparation of cellulose sulfate and evaluation of its properties. Journal of Fiber Bioengineering and Informatics 3:32-39

Kuznetsov BN, Kuznetsova SA, Levdansky VA, Levdansky AV, Vasil'eva NYu, Chesnokov NV, Ivanchenko NM, Djakovitch L, Pinel C (2015) Optimized methods for obtaining cellulose and cellulose sulfates from birch wood. Wood Sci Technol 49:825-843

Kuznetsov BN, Sudakova IG, Garyntseva NV, Djakovitch L, Pinel C (2013) Kinetic study of aspen-wood sawdust delignification by $\mathrm{H}_{2} \mathrm{O}_{2}$ with sulfuric acid catalyst under the mild conditions. Reac Kinet Mech Cat 110:271280

Kuznetsov BN, Tarabanko VE, Kuznetsova SA (2008) New catalytic methods for obtaining cellulose and other chemical products from vegetable biomass. Kinet Catal + 49:517-526

Lin N, Huang J, Dufresne A (2012) Preparation, properties and applications of polysaccharide nanocrystals in advanced functional nanomaterials: a review. Nanoscale 4:3274-3294

Nishiyama Y, Langan P, Chanzy H (20002) Crystal structure and hydrogen-bonding system in cellulose I $\beta$ from synchrotron X-ray and neutron fiber diffraction. J Am Chem Soc 124:9074-9082

Park S, Baker JO, Himmel ME, Parilla PA, Jonson DK (2010) Cellulose crystallinity index: measurement techniques and their impact on interpreting cellulase performance. Biotechnol Biofuels 3:10

Qin Z, Ji L, Yin X, Zhu L, Lin Q, Qin J (2014) Synthesis and characterization of bacterial cellulose sulfates using a $\mathrm{SO}_{3} /$ pyridine complex in DMAc/LiCl. Carbohyd Polym 101:947-953

Oberlerchner JT, Rosenau T, Potthast A (2015) Overview of Methods for the Direct Molar Mass Determination of Cellulose. Molecules 20: 10313-10341

Rossberg C, Steffien D, Bremer M, Koenig S, Carvalheiro F, Duarte LC, Moniz P, Hoernicke M, Bertau M, Fischer S (2014) Pulp properties resulting from different pretreatments of wheat straw and their influence on enzymatic hydrolysis rate. Bioresource Technology $169: 206-212$.

Roy D, Semsarilar M, Guthrie JT, Perrier S (2009) Cellulose modification by polymer grafting: a review. Chem Soc Rev 38: 2046-2064

Shibata T (2011) Cellulose and Its Derivatives in Medical Use. In: Peter A Williams (ed) Renewable Resources for Functional Polymers and Biomaterials: Polysaccharides, Proteins and Polyesters, RSC Publishing; Cambridge, pp 48-87

Sixta H (2006) Handbook of pulp. Wiley - VCH Verlug SmbH \& Co, Weinheim, Germany

Sjöström E, Alen R (1999) Analytical methods in wood chemistry, pulping and papermaking. Springer Series in Wood Science, Springer-Verlag, Berlin

TAPPI (1998) (acid- insoluble lignin in wood and pulp-T222 om-02)

Wagenknecht W, Nehls I, Philipp B (1993) Studies on the regioselectivity of cellulose sulfation in an $\mathrm{N}_{2} \mathrm{O}_{4}-\mathrm{N}_{\text {, }} \mathrm{N}-$ dimethylformamide-cellulose system. Carbohyd Res 240:245-252 
Wang ZM, Li L, Xiao KJ, Wu JY (2009) Homogeneous sulfation of bagasse cellulose in an ionic liquid and anticoagulant activity. Bioresource Technol 100:1687-1690

Wang ZM, Li L, Zheng BS, Normakhamatov N, Guo SY (2007) Preparation and anticoagulation activity of sodium cellulose sulfate. Int J Biol Macromol 41:376-382

Wang J, Huang H, Huang X (2016) Molecular weight and the Mark-Houwink relation for ultra-high molecular weight charged polyacrylamide determined using automatic batch mode multi-angle light scattering. J. Appl. Polym. Sci 133: 43748-43755

Zhang K, Brendler E, Fischer S (2010) FT Raman investigation of sodium cellulose sulfate. Cellulose 17:427-435

Zhang K, Brendler E, Geissler A, Fischer S (2011) Synthesis and spectroscopic analysis of cellulose sulfates with regulable total degrees of substitution and sulfation patterns via ${ }^{13} \mathrm{C}$ NMR and FT Raman spectroscopy. Polymer 52:26-32

Zhang Q, Lin D, Yao S (2015) Review on biomedical and bioengineering applications of cellulose sulfate. Carbohyd Polym 132:311-322

Zhu L, Qin J, Yin X, Ji L, Lin Q, Qin Z (2014) Direct sulfation of bacterial cellulose with a ClSO ${ }_{3} \mathrm{H} / \mathrm{DMF}$ complex and structure characterization of the sulfates. Polym Advan Technol 25:168-172 